\section{Increasing fruit and vegetable intake with reservation and off-reservation kindergarten students in Nevada}

\author{
Staci Emm, ${ }^{*}$ * Jessica Harris, ${ }^{\mathrm{b}}$ Judy Halterman, ${ }^{\mathrm{c}}$ \\ Sarah Chvilicek, ${ }^{\mathrm{d}}$ and Carol Bishop ${ }^{\mathrm{e}}$ \\ University of Nevada Cooperative Extension
}

\section{Special JAFSCD Issue \\ Indigenous Food Sovereignty in North America sponsored by Swette Center for
Sustainable Food Systems Arizona State University}

Citation: Emm, S., Harris, J., Halterman, J., Chvilicek, S, \& Bishop, C. (2019). Increasing fruit and vegetable intake with reservation and off-reservation kindergarten students in Nevada. Journal of Agriculture, Food Systems, and Community Development, 9(Suppl. 2), 215-224. https://doi.org/10.5304/jafscd.2019.09B.014

Copyright (C) 2019 by the Authors. Published by the Lyson Center for Civic Agriculture and Food Systems. Open access under CC-BY license.

\author{
Abstract \\ American Indian tribes historically survived on \\ hunting, gathering, and farming activities. As \\ federal policy changed, reservations were estab- \\ lished, which limited some of these hunting and \\ gathering activities. Nevada is home to Washoe, \\ Shoshone, and Paiute American Indians. There are \\ * Corresponding author: Staci Emm, Professor and Extension \\ Educator, University of Nevada Cooperative Extension; \\ Mineral County Cooperative Extension; P.O. Box 810; \\ Hawthorne, NV 89415 USA; +1-775-475-4227; \\ emms@,unce.unr.edu \\ b Jessica Harris, Community-based Instructor III, University \\ of Nevada Cooperative Extension; harrisi@unce.unr.edu \\ c Judy Halterman, Community-based Instructor III, University \\ of Nevada Cooperative Extension; haltermanj@unce.unr.edu \\ d Sarah Chvilicek, Administrative Faculty Program and \\ Program Manager, Washoe County 4-H Youth Development \\ Programs, University of Nevada Cooperative Extension; \\ chviliceks@unce.unr.edu \\ e Carol Bishop, Assistant Professor and Extension Educator, \\ University of Nevada Cooperative Extension; \\ bishopc@unce.unr.edu
}

19 federally recognized American Indian tribes with 27 reservations and colonies geographically dispersed across the state of Nevada. Several of these reservations are near Nevada's small, rural towns where access to fruits and vegetables is limited. Often, the residents of small rural towns next to the reservation are unaware of the tribal cultural history. University of Nevada Cooperative Extension created an elementary nutrition education program called Veggies for Kids, for use in reservation schools and off-reservation schools under the U.S. Department of Agriculture (USDA) Supplemental Nutrition Assistance Program-Education (SNAPEd). The Veggies for Kids program utilizes traditional foods, tribal language, and gardening experiences as building blocks to introduce healthy eating and increase fruit and vegetable intake among elementary students. For the 2017-2018 school year, pre- and post-test data were collected from 45 American Indian kindergarten students attending schools on reservations and 486 kindergarten students in off-reservation schools located next to a reservation. Methods of data analysis included descriptive statistics, paired sample t-tests, and 
nonparametric McNemar testing. Results from the kindergarten data showed an increase in test scores of students correctly identifying USDA's MyPlate food groups, naming selected fruits and vegetables provided during the program, self-reporting water consumption, and selecting physical activity. Cumulative student test scores for all kindergarten data were statistically significant at $p$-value $<.001$.

\section{Keywords}

American Indian (AI), Vegetables, Fruits, Traditional Food, Native Language, SNAP-Ed, Schoolchildren, Nutrition, School Gardens

\section{Introduction and Literature Review}

Food sovereignty, in its truest sense, is the ability of a population or person to dictate what is a culturally, ecologically, and sustainable food source and to define their own food and agricultural systems. American Indian Tribes in the United States theoretically should be able to do this. The reality is that it does not happen quickly. Federal policy regarding American Indians in the U.S. has perpetuated a dependency for food access. Historically, this has increased the amounts of processed foods available through commodity programs. At the same time, land policies have limited access by American Indians to lands that are rich in traditional foods such as wild berries, onions, carrots, venison, elk, groundhog, and ground squirrels. There are some Tribes in Nevada fighting for true food sovereignty; however, it is a difficult road as most are dependent upon federal programs and funding with dictated regulations and food sources. Nevada tribes do not want their native language and the knowledge of traditional food sources to disappear. This paper discusses a program that was created with Nevada tribes under Nevada's Supplemental Nutrition Assistance Program-Education (SNAP-Ed) as a first step toward increasing the knowledge of youth regarding traditional foods and tribal language, while recognizing the federally mandated MyPlate nutrition guide with recommended portions of fruits, vegetables, protein, dairy, and grains.

There are Paiute, Shoshone, and Washoe Indians in Nevada that represent 19 federally recognized tribes and 27 reservations and colonies.
Each tribe in Nevada has a unique story. The Paiute people are made up of many different bands of Indians who historically were located across a large part of the western U.S. The Paiute call themselves "Numu," meaning "The People." In Nevada, there are Southern Paiute and Northern Paiute. The Southern Paiute, prior to contact with Europeans, occupied more than 30 million acres (12 million hectares) of present-day southern California, southern Nevada, south-central Utah, and northern Arizona. The Northern Paiute in Nevada lived in several bands that spanned Oregon, California, Nevada, and Idaho.

The Western Shoshone Indians are "Newe," also meaning "The People," with a traditional territory covering southern Idaho, the central part of Nevada, northwestern Utah, and the Death Valley region of southern California. The Western Shoshone historically survived by hunting, gathering, fishing, foraging, and some farming. There are four federally recognized tribes that are both Northern Paiute and Shoshone.

For the majority of the Nevada Tribes, land was purchased, set aside, or allocated by the federal government for the Indians living in the area. In other cases, officials relocated groups of Indians to a particular land base. This resulted in Paiute and Shoshones making up one tribe located on a specific Nevada reservation.

The Washoe Tribe of Nevada and California is located in western Nevada and eastern California around Lake Tahoe. The tribe is made up of five bands and resides on about 10 separate tracts of land. The Washoe people call themselves "Wašiw" (Washoe Tribe of Nevada and California, 2009).

Most tribes in Nevada participated in hunting, gathering, and farming to provide for a remarkably holistic and diverse food supply. This traditional diet was a mix of plants and animals that are not characteristic of today's modern diet. The tribes use a distinctive traditional knowledge passed down through elders that integrates a spiritual connection to food and the land (Milburn, 2004).

The reservation era in the U.S. commenced in 1850, and reservations in Nevada were created between 1886 through 1939. As the land bases were established for Nevada Tribes, tribal members' access to hunting and gathering areas became 
limited. In addition, there were not always water resources available for farming (Emm \& Singletary, 2009). It became more difficult to maintain a diet from traditional food sources. Federally recognized tribal status of these reservations resulted in access to a federal commodity food program, the Food Distribution Program on Indian Reservations (FDPIR), that was introduced in 1977.

Before and at the same time reservations were being established, the gold rush brought prospectors to Nevada, while the Homestead Act brought farmers and ranchers who settled territory. The diet of the settlers was based on what they had access to, which was mostly plants (berries, wild onions, pine nuts) and animals (deer, groundhog, ground squirrel, and fish). Individuals living in rural Nevada communities that border reservations or are in close proximity to the reservations usually have a connection to the reservation in some way. This can be both a positive or negative connection, as it brings two different worlds together, the Indian and the non-Indian. Food systems do not always stop at reservation boundaries and are not always based on ethnic differences, but rather by food access. For this reason, there was an opportunity in Nevada to bridge the gap between onreservation nutrition education and off-reservation nutrition education based on food access, especially fruits and vegetables.

FDPIR, also known as "commodities," is part of the standard of living on most reservations, as all tribes in Nevada participate in the program. Commodity cheese and flour are a regular part of the Nevada tribal diet, but were not part of the traditional foods systems of these tribes. Research that assessed the Supplemental Nutrition Assistance Program for Women, Infants, and Children (WIC) indicates that WIC food vouchers have a significant effect on the behavior of children who participate in the program eating processed foods (Companion, 2013). Revising the WIC food vouchers to allow the purchase of fruits, vegetables, and whole grains led to increased consumption of healthful foods among American Indian children (Companion, 2013). This raises questions regarding access to foods among American Indians, and whether access determines diet. Food consumption among poorer populations and American Indians mirrors that of nutritional evolution dominated by access to prepackaged foods high in fat, sugar, sodium, and with an extended shelf life (Companion, 2013).

The Veggies for Kids kindergarten curriculum created in 2013 by the University of Nevada Cooperative Extension utilizes traditional American Indian knowledge of foods and language to increase fruit and vegetable intake among kindergarten students attending schools on a reservation or near a reservation. Most children of tribal members attend the rural local schools next to the reservations; only three elementary schools are on Nevada reservations.

A 2004 study of leading health education teachers indicated that in-classroom programs improved dietary behavior, increased physical activity, and reduced sedentary behavior (U.S. Centers for Disease Control and Prevention, 2006). In-school nutrition education programs integrated into the overall health and wellness of a school promote the consumption of healthful foods (McKenna, 2010). The Veggies for Kids program was created by integrating U.S. Department of Agriculture guidelines (U.S. Department of Health and Human Services \& U.S. Department of Agriculture, 2015) and the traditional knowledge of Nevada participating Tribes: the Walker River Paiute, Pyramid Lake Paiute, and Duck Valley Paiute and Shoshone. Funding for Veggies for Kids has come from SNAP-Ed. The core goals of the Veggies for Kids program are:

- Reinforce the importance and integration of nutrition education in schools, with lesson content linked to Nevada education standards.

- Promote adequate intake of vegetables and fruits through increased exposure to them.

- Promote the use of water and low-fat milk as preferred beverages over sweetened beverages.

- Promote daily physical activity.

- Reinforce American Indian cultural connections to traditional health, promoting behavior through the use of traditional foods, food gathering, and Paiute and Shoshone translations. 
- Provide an introduction to gardening through in-class experiences and school gardens.

- Engage parents through take-home assignments.

Traditional foods, food gathering, and tribal language are reinforced by having tribal elders participate in the program. Tribal elders go into the schools for a cultural day and talk about the traditional foods that were and are available, how they are harvested, and how they are used. Native languages are based on descriptors. For this reason, colors of fruits and vegetables were translated with tribal words for root, fruit, and sprout (so apple is translated as "red fruit," for example). In addition, there were tribal translations for muscles, mind, lungs, and heart for growing strong. There are also lessons on gardening and growing your own vegetables.

A policy, systems, and environmental (PSE) approach is taken with Veggies for Kids, since classroom instruction is only one part of a school's coordinated efforts. The curriculum encourages gardening activities and is combined with a school or community garden. This includes the use of seasonal extensions such as a hoop house. Teachers, students, and community volunteers were encouraged to participate in growing traditional native foods. "Smarter Lunchroom"1 activities were created to encourage students to drink more water instead of sugar-sweetened drinks. Program banners were put outside the school so that communities can recognize a Veggies for Kids school.

Modern diets are described as calorie-dense and nutrient-poor, while traditional indigenous diets are described as nutrient-rich and calorielimited (Milburn, 2004). For example, wild game is higher in many nutrients and leaner than domesticated meats. It is important to introduce the concept of farm to fork to teach students that their food does not originally come from the grocery store. Closing the gap and eliminating the distance between growing and eating food is an important concept reinforced in the Veggies for Kids pro- gram.

Through diverse methodology, the Veggies for Kids program attempts to support positive behavioral change through in-classroom education and environmental change based on food access. Raising youth awareness of MyPlate, fruits and vegetables, water consumption, and physical activity contributes to the ongoing national efforts to promote healthful diets and healthy weight (Office of Disease Prevention and Health Promotion [ODPHP], 2019). Introducing students to Paiute and Shoshone traditional food such as wild onions, buck berries, and pine nuts brings the current and past worlds together. However, the program is restricted in bringing traditional foods into the classroom, due to health regulation, because they are not prepackaged. For this reason, the curriculum evaluation measures foods that students have access to both on and off the reservation.

\section{Applied Research Methods}

The Veggies for Kids program has been practicebased under SNAP-Ed for several years, and the authors are working on getting the program to be evidence-based. The University of Nevada, Reno Institutional Review Board (IRB) has reviewed the pre-test and post-test evaluation instruments, parent letters, and passive consent forms sent home with students. Pre- and post-tests were used for data collection and analysis, while the parent letters were sent out by the school to notify parents about the program and to ask about student allergies. The passive consent forms also were sent home with students; parents needed to sign and return the form to opt their child out of the program.

The Veggies for Kids program utilized a pre/post survey methodology to collect data at the beginning of the program and again at the end of the program. The pre- and post-tests are identical. The tests were printed and distributed to each instructor to begin their program. All instructors were trained on how to implement the pre-test and post-test surveys to kindergarten students. Consistency in language and survey methods was essential for obtaining accurate data.

\footnotetext{
1 The Smarter Lunchrooms Movement is a program under SNAP-Ed to utilize research-based practices to get children to eat healthy meals, increase their vegetable and water intake, etc.
} 
Each of the participating 13 school sites began week one with a student pre-test, followed by 12 consecutive weekly lessons, and ended with a posttest after the twelfth lesson. Testing was conducted individually, with each student tested and observed outside the classroom or in a quiet location within the classroom. The test was proctored by the trained Veggies for Kids instructor, and all questions were asked and responses written by the instructor. Each individual testing session took between five and 10 minutes to complete, depending on the student's skill set.

Students were asked to identify the five food groups of MyPlate. Students were also asked to name six selected fruits and vegetables that were seen and tasted during programming. They were asked to state their preference or likability for each of these six fruits and vegetables. To identify water consumption, students were asked to recall how many drinks of water they took the day prior. This included identifying drinks at home, at school, in the lunchroom, and at a drinking fountain.

"Play hard" is a term introduced in the program that has the same definition as physical activity. Students were asked to choose two photos that demonstrated play hard activities in the pre- and post-test. The instructors observed the students to see if they select two "playing hard" photos or if they chose a sedentary behavior, which determined if the student understood the term "play hard."

Impact data obtained from the kindergarten pre- and post-tests were analyzed using Statistical Package for the Social Sciences (SPSS, 2018) to measure short-term knowledge gains. All student responses, aside from water consumption, were dichotomized as correct versus incorrect, and individual questions and cumulative questions scores were calculated. Cumulative pre- and post-test mean scores were calculated using a paired samples t-test. Individual question percent correct scores were provided through descriptive statistics, while individual question pre- and post-test mean scores were calculated using nonparametric McNemar tests. Answers, whether correct or incorrect, were not discussed with the students after testing; however, if a vegetable or fruit was identified incorrectly by the student, they were told the correct name to ensure their response to the subsequent "have you tasted it before" questions were valid.

The majority of American Indian students who participated in the 2017-2018 Veggies for Kids program were in higher grades, but 45 American Indian kindergarten students participated in the program. The data reflect kindergarten analysis only, to assess the efficacy of the kindergarten curriculum. Descriptive statistics were run to demonstrate percent correct for pre- and post-tests questions. Paired sample t-tests were performed for pre- and post-test cumulative data. Scores from the MyPlate recognition question, MyPlate food group naming questions, vegetable and fruit identification, willingness to try questions, and play hard question were compiled. Paired sample t-tests produced pre- and post-test mean scores, mean differences, and 2-tailed $p$-values for cumulative kindergarten scores. With an alpha of .05, McNemar tests were performed to assess whether a statistically significant change occurred for each dichotomous question (19 in total) between pre- and posttesting.

\section{Results}

Pre- and post-test data were collected from 45 American Indian kindergarten students attending schools on reservations and 486 kindergarten students in off-reservation schools located next to a reservation. The cumulative pre- and post-test mean scores, mean differences, and 2-tailed $p$ values produced from paired sample t-tests are provided in Table 1 for off-reservation kindergarten students and on-reservation American Indian kindergarten students. For off-reservation kindergarten students $(n=486)$, the mean difference between scores was 6.17 , and for on reservation American Indian kindergarten students $(n=45)$, the mean difference was 6.02. $P$-values $<.0001$ were observed for off-reservation kindergarten students and American Indian kindergarten students.

At the beginning and end of the in-classroom direct education program, students were shown a graphic of USDA's MyPlate and asked if they had seen the graphic before. Pre-test data, for offreservation kindergarten students, showed that $38 \%$ of students self-reported that they had seen the graphic before, while post-test data showed that $91 \%$ of students self-reported they had seen 
Table 1. Mean Score, Mean Difference, and $p$-values from Paired-Sample T-Tests for On-reservation and Off-reservation Kindergarten Students

\begin{tabular}{lccccc}
\hline Paired Sample T-Test & $n$ & Pre-test Mean (SD)* $^{*}$ & Post-test Mean (SD)* & $\mu^{* *}$ & $p$-value \\
\hline Kindergarten Students & 486 & $7.62(2.35)$ & $13.79(3.16)$ & 6.17 & .0000 \\
\hline American Indian Kindergarten Students & 45 & $8.02(2.45)$ & $14.04(3.32)$ & 6.02 & .0000 \\
\hline
\end{tabular}

* $\mathrm{SD}=$ standard deviation; * $\mu \mathrm{d}=$ difference of means

Table 2. Comparison of On-reservation Kindergarten Students and Off-reservation Kindergarten Students Correctly Identifying MyPlate Food Groups

\begin{tabular}{lcccr}
\hline & & & \multicolumn{2}{c}{$\begin{array}{c}\text { Off-reservation } \\
\text { Kindergarten }(n=486)\end{array}$} \\
\cline { 2 - 5 } MyPlate Food Group & On-reservation Kindergarten $(n=45)$ & Pre-test & Post-test \\
\hline Fruits & Pre-test & Post-test & .035 & .741 \\
\hline Vegetables & .044 & .822 & .029 & .743 \\
\hline Protein & .044 & .756 & .008 & .516 \\
\hline Grains & .000 & .622 & .008 & .510 \\
\hline Dairy & .000 & .622 & .012 & .708 \\
\hline
\end{tabular}

the graphic after completion of the 12 in-school lessons. For the American Indian kindergarten data, the same MyPlate recognition question was asked, with pre-test results showing $47 \%$ of students self-reporting that they had seen the graphic before, and post-test results showing $87 \%$ of students had seen it after the in-school lessons. For both cumulative kindergarten and American Indian-specific data, McNemar tests for MyPlate identification were statistically significant at a $p$ value $<.001$.

Table 2 shows the percentage of off-reservation kindergarten students who could correctly name the five MyPlate food groups from pre-test to post-test. Pre-test scores ranged from $0.8 \%$ to $4.0 \%$ correct, while post-tests scores ranged from $51 \%$ to $74 \%$ correct. Table 2 also shows the percentage of on-reservation American Indian kindergarten students who could correctly name the five MyPlate food groups between pre- and post-test. Pre-test scores ranged from $0 \%$ to $4 \%$ correct, while post-tests scores ranged from $62 \%$ to $82 \%$ correct. McNemar tests for each food group indicator were statistically significant at $p<.001$ for offreservation kindergarten students and American Indian kindergarten students.

Table 3 shows the percentage of kindergarten students who correctly named selected fruits and vegetables before and after the in-school instruction. Of the 12 questions (naming and willingness to try six selected fruit and vegetables), all except two had statistically significant results between preand post-test at $p$-values $<.001$.

Table 4 shows the percentage of American Indian students who correctly named selected fruits and vegetables before and after the in-school instruction. Of the 12 questions (naming and willingness to try six selected fruit and vegetables), only asparagus, blueberry, squash, lemon, and spinach identification questions and the tasting of squash question were statistically significant at $p<.01$.

Play hard results were measured for all kindergarten students. The play hard percent correct for pre- and post-tests for off-reservation kindergarten students were $60 \%$ and $91 \%$, respectively. The play hard percent correct for pre- and post-tests for American Indian kindergarten students were 64\% and $78 \%$, respectively.

For off-reservation kindergarten students, selfreported daily water consumption at pre- and posttest for $0-4$ drinks per day were $46 \%$ and $32 \%$; 5 10 drinks per day were $29 \%$ and $33 \% ; 11-15$ drinks per day were $9 \%$ and $9 \%$; and $16+$ drinks per day 
Table 3. Off-reservation Students Able to Correctly Name and their Willingness to Try Selected Fruits and Vegetables

\begin{tabular}{|c|c|c|c|}
\hline Correctly Naming Fruits and Vegetables $(n=486)$ & Pre-test & Post-test & $p$-value \\
\hline What is the name of Asparagus? & .080 & .290 & .0000 \\
\hline Have you tasted it before? & .393 & .720 & .0000 \\
\hline What is the name of Blueberry? & .755 & .897 & .0000 \\
\hline Have you tasted it before? & .844 & .914 & .0004 \\
\hline What is the name of Squash? & .095 & .479 & .0000 \\
\hline Have you tasted it before? & .379 & .739 & .0000 \\
\hline What is the name of Lemon? & .685 & .854 & .0000 \\
\hline Have you tasted it before? & .815 & .870 & .0076 \\
\hline What is the name of Spinach? & .082 & .233 & .0000 \\
\hline Have you tasted it before? & .597 & .856 & .0000 \\
\hline What is the name of Strawberry? & .899 & .967 & .0000 \\
\hline Have you tasted it before? & .924 & .936 & .4881 \\
\hline
\end{tabular}

were $14 \%$ and $26 \%$, respectively. For on-reservation kindergarten students, daily water consumption at pre- and post-test for $0-4$ drinks per day were $51 \%$ and $43 \% ; 5-10$ drinks per day were $36 \%$ and $33 \% ; 11-15$ drinks per day were $2 \%$ and $2 \%$; and $16+$ drinks per day were $11 \%$ and $20 \%$, respectively.

\section{Discussion}

By utilizing traditional foods and tribal language, Veggies for Kids lays the foundation to introduce nutritional concepts and support positive behavior change among kindergarten students in rural areas of Nevada, either on- or off-reservation. The Veggies for Kids program effectively meets its goals aimed at increasing fruit and vegetable recognition, water consumption, and physical activity based on evaluation of the program. Future work will focus on traditional foods available in the areas and evaluating students' increased knowledge of traditional foods on and off the reservations.

Results from the 2017-2018 data indicate sig-

Table 4. On-reservation Students Able to Correctly Name and Their Willingness to Try Selected Fruits and Vegetables

\begin{tabular}{lccc}
\hline Correctly Naming Fruits and Vegetables $(\boldsymbol{n}=\mathbf{4 5})$ & Pre-test Correct & Post-test Correct & P-value \\
\hline What is the name of Asparagus? & .022 & .267 & .0010 \\
\hline \multicolumn{1}{c}{ Have you tasted it before? } & .556 & .600 & .8036 \\
\hline What is the name of Blueberry? & .622 & .889 & .0042 \\
\hline$\quad$ Have you tasted it before? & .844 & .889 & .7266 \\
\hline What is the name of Squash? & .200 & .600 & .0001 \\
\hline Have you tasted it before? & .511 & .778 & .0042 \\
\hline What is the name of Lemon? & .622 & .911 & .0010 \\
\hline Have you tasted it before? & .733 & .800 & .5488 \\
\hline What is the name of Spinach? & .089 & .378 & .0002 \\
\hline Have you tasted it before? & .644 & .000 \\
\hline What is the name of Strawberry? & .978 & 1.00 & 1.0000 \\
\hline Have you tasted it before? & .956 & .933 \\
\hline
\end{tabular}


nificant knowledge gains across multiple indicators for off-reservation kindergarten students and American Indian kindergarten students. There was a statistically significant increase in knowledge of students recognizing the image of MyPlate. The difference in pre- and post-test percent correct scores for the MyPlate recognition question were $52 \%$ and $40 \%$ for off-reservation kindergartners and American Indian kindergartners, respectively. The difference in pre- and post-test scores indicate that the Veggies for Kids classes were effective in raising awareness and recognition of USDA's MyPlate. Additionally, statistical significance was observed with students correctly naming the five MyPlate food groups.

Identifying the MyPlate food groups encourages healthy behavior and increases student awareness of the foods they eat and their nutritional value. Student ability to name six selected fruits and vegetables increased between pre- and posttesting. Off-reservation students had statistically significant results for all six fruits and vegetables, indicating that the program successfully affected student recognition and short-term knowledge gains. For the American Indian students, all selected fruit and vegetable scores, except strawberries, increased statistically between pre- and post-testing,. The results show that recognition of selected fruits and vegetables that were introduced during programming increased among kindergarten students at both reservation and off-reservation schools. These data suggest that raising the awareness of fruits and vegetables increases the likelihood of future consumption and further encourages healthy eating behavior.

In conjunction with increased awareness of MyPlate and selected fruits and vegetables, student awareness of physical activities increased. Offreservation kindergarten students had a 31\% difference between pre- and post-testing, while American Indian kindergarten students had a 13\% difference, indicating increased short-term knowledge gains. While on-reservation kindergarten results were not statistically significant $(p>.05)$, the percent difference shows that students' ability to select physical activity photos over sedentary photos increased. Recognizing physical activities is practically significant, as it contributes to increased phys- ical activity and knowledge of healthful behaviors.

Water consumption was also tested. Pretest results showed that students selected the lowest water consumption answer ( $0-4$ drinks per day) more frequently than any other option, $46 \%$ and $51 \%$ for off-reservation kindergarten students and American Indian kindergarten students, respectively. Post-test results showed a lowered selection of $0-4$ drinks per day and increased selection of $16+$ drinks per day. The difference in results indicates that students were self-reporting a higher consumption of water at post-testing. Increased water consumption has the potential to influence other beverage choices, but more importantly reflects an increase in healthy behavior. Water consumption is essential for growth and development and is an important goal of the Veggies for Kids program. Current research on the program continues to focus on the most appropriate way to evaluate water consumption as there are limitations with asking youth to self-report water intake.

\section{Conclusion}

Data analysis of the 2017-2018 Veggies for Kids kindergarten results indicate that the program was effective in raising student knowledge of MyPlate, selected fruits and vegetables, physical activity, and influencing water consumption among both offreservation kindergarten students and on-reservation American Indian kindergarten students. The achievement of program indicators corresponds to one of the Healthy People 2020 goals, which aims to promote health and reduce chronic disease risk through the consumption of healthful diets and achievement and maintenance of healthy body weights (ODPHP, 2019).

The Veggies for Kids programming efforts aim to influence environmental change in the classroom and improve overall school health. Environmental change is related to access and what the students have available to them. The Veggies for Kids program is able to continue the goals of Healthy People 2020 for rural Nevada students by supporting healthful diets and physical activity opportunities.

There are a few potential limitations that could have affected the findings from these analyses. First, county nutrition policies could have limited 
the abilities of each nutrition instructor. Some school districts implemented sugar policies and exemptions that could have affected the child behavior choices reflected in our testing. This means that a student's decision to drink a sugary beverage at school may have been affected by policy rather than direct programming. Second, testing fidelity among nutrition instructors could have been compromised, as the majority of instructors both taught the students and collected data. Testing fidelity was expected, and detailed testing instructions were provided in-person and via phone; however, tests were unsupervised, which could allow for infidelity. Third, curriculum fidelity, in the same manner, may have been a problem. With 13 schools across four counties, teaching was anticipated to vary slightly; however, it was impossible to supervise all teachers, leading to potential curriculum fidelity problems. Finally, the team is always looking for improved ways of evaluating the efficacy of the program. Self-reporting is seen as the most effective way at this time, but this evaluation method could change over time.

It is unlikely that limitations would drastically change the results of the findings. A randomized control intervention is being conducted for the 2018-2019 school year among kindergarteners in one Nevada county. The randomized control intervention will provide identical data, which will be used for comparative analyses and further evaluations into the effectiveness of the kindergarten curriculum content. It is anticipated that the findings from the randomized control intervention will mirror the results of the 2017-2018 kindergarten data.

The program team will continue to work with traditional food access and overall food access for reservation and rural communities in Nevada. The team continues to work with school districts in educating administrators, cooks, teachers, and students about traditional foods and how they can be gathered in a safe way to ensure food safety. The program is also expanding funding sources so that it is not tied only to SNAP-Ed requirements. This will allow the program to expand and be focused more on traditional foods, language, tribal food access, and tribal food sovereignty.

Future evaluation needs to address schools and local grocery stores integrating traditional foods, such as buck berries, pine nuts, and venison, into school activities and the wider food systems. This is an environmental change that needs to occur with work through USDA school lunchroom guidelines and tribal governments. In addition, research needs to be done on the increase of knowledge of traditional foods, and what impact that has on communities, such as diabetes and/or obesity rates.

\section{Acknowledgments}

The authors would like to thank Alyssa O'Hair of the Center for the Application of Substance Abuse Technologies (CASAT), who spent countless hours of her time sharing her data analysis expertise and knowledge.

\section{References}

Companion, M. (2013). Obesogenic cultural drift and nutritional transition: Identifying barriers to healthier food consumption in urban Native American populations. Journal of Applied Social Science, 7(1), 80-94. https://doi.org/10.1177/1936724412467022

Emm, S., \& Singletary, L. (2009). People of the land (Report no. CM-09-01). Reno: University of Nevada Cooperative Extension.

McKenna, M. L. (2010). Politiques visant à favoriser une saine alimentation dans les écoles [Policy options to support healthy eating in schools]. Canadian Journal of Public Health, 101(Suppl. 2), S14-S18. https://doi.org/10.1007/BF03405619

Milburn, M. P. (2004). Indigenous nutrition: Using traditional food knowledge to solve contemporary health problems. The American Indian Quarterly, 28(3\&4), 411-434. https://doi.org/10.1353/aiq.2004.0104

Office of Disease Prevention and Health Promotion. (2019, January). 2020 topics \& objectives: Nutrition and weight status. Retrieved from https://www.healthypeople.gov/2020/topics-objectives/topic/nutrition-and-weight-status

U.S. Centers for Disease Control and Prevention. (2006, August 4). Secondary school health education related to nutrition and physical activity — Selected sites, United States, 2004. Morbidity and Mortality Weekly Report, 55(30), 821-824. Retrieved from https://www.cdc.gov/mmwr/PDF/wk/mm5530.pdf 
U.S. Department of Health and Human Services \& U.S. Department of Agriculture. (2015). Dietary Guidelines for American. 2015-2020. Retrieved from https://health.gov/dietaryguidelines/2015

Washoe Tribe of Nevada and California. (2009). Wa She Shu: "The Washoe People" Past and Present. Retrieved from https://washoetribe.us/about/washoe-history.html 